\title{
Estudo da dinâmica da paisagem sob influência do plantio de eucalipto em Matões/MA entre os anos 2008 e 2015
}

\author{
Study of landscape dynamic under the influence of eucalyptus plantation in \\ Matões/MA between the years 2008 and 2015
}

ANDRADE $^{1}$, F. H. S.; MOURA ${ }^{2}$, L. S.

felipegeo@outlook.com

\begin{abstract}
Resumo
A pesquisa tem como objetivo estudar a dinâmica da paisagem sob influência dos impactos decorrentes da introdução do cultivo do eucalipto no município de Matões/MA entre 2008 e 2015. As seguintes questões nortearam a investigação: Como o plantio de eucalipto está afetando a dinâmica da paisagem no município de Matões/MA? A implantação dessa monocultura leva em conta as características naturais da área em que está instalada? A abordagem da pesquisa é quali-quantitativa, e para tanto se procedeu com revisão bibliográfica, pesquisa de campo para observação, marcação de pontos em GPS, registro fotográfico e preenchimento de planilhas de campo e fase de gabinete para elaboração de mapas de uso da terra por meio do tratamento dos dados em ambiente SIG. Os resultados apontam que houve expansão de $6,87 \%$ da área plantada com eucalipto para os períodos de 2008 a 2015. Através da pesquisa foi possível o reconhecimento dos impactos do plantio e a distribuição da monocultura do eucalipto ao longo da área do município.
\end{abstract}

Palavras-chave: Cartografia de paisagens. Plantio de eucalipto. Matões/MA.

\begin{abstract}
The research has as main objective to study the dynamics of the landscape under the influence of impacts resulting from the introduction of eucalyptus cultivation in the county of Matões / MA between 2008 and 2015. The following questions guide the research: How the eucalyptus plantation is affecting the landscape dynamics in the city? The implementation of this monoculture takes into account the natural characteristics of the area in which they are installed? The research approach is qualitative and quantitative, and so it was performed bibliographic review and field research for observation and photographic record.It is also used GIS techniques. Considering the land use maps drawn up by the county orbital images and the data from public agencies, it found that there was an increase of $6.87 \%$ of the area planted with eucalyptus for the periods from 2008 to 2015. Through research was recognized the impacts of planting and distribution of eucalyptus monoculture throughout the municipal area.
\end{abstract}

Keywords: Landscapes mapping. Eucaliptus plantation. Matões/MA.

\section{INTRODUÇÃO}

O estudo da paisagem é importante, para diversas ciências da terra que estudam os componentes da superfície terrestre (rochas, solos, vegetação e a água), bem como na compreensão da dinâmica do meio natural e no estabelecimento de legislação para uso ocupação e proteção.

Em relação à origem da paisagem Vitte (2007) analisa que esta resulta das intenções humanas sobre a superfície da Terra, através dos meios técnicos e científicos, no decorrer do tempo. Para ele "a sociedade imprime sua marca no espaço que fica registrada na paisagem. Assim, a paisagem é uma representação do espaço. Na Ciência Geográfica e particularmente na geografia física, a paisagem passa a ser o sinônimo de natureza" (VITTE, 2007, p.77).

Conhecer o espaço ao seu redor sempre constituiu uma das necessidades do homem, e uma das formas mais utilizadas para obter tal conhecimento e expressá-lo, foi através da construção de ${ }^{1}$ Felipe Henrique da Silva Andrade, Núcleo de Estudos sobre a Zona Costeira do Estado do Piauí - NEZCPI, Universidade Estadual do Piauí, Teresina-PI, Brasil.

${ }^{2}$ Liége de Souza Moura., Núcleo de Estudos sobre a Zona Costeira do Estado do Piauí - NEZCPI, Universidade Estadual do Piauí, Teresina-PI, Brasil. 
mapas, que sempre teve importância para a Geografia, pois possibilita trabalhar dados que se encontram distribuídos espacialmente, além de constituir um objeto de investigação na compreensão de fatos e coleta de dados para análises. Deste modo, para a representação da paisagem a cartografia se apresenta como ferramenta essencial e "a representação cartográfica das paisagens exige um inventário geográfico completo e relativamente detalhado" (BERTRAND, 2004, p. 151).

A cartografia de paisagens do ponto de vista epistemológico "é uma área da Cartografia Temática e a Geografia Física Integrada" (CAVALCANTI, 2014, p.07). O autor salienta que pela sua própria base epistemológica a cartografia de paisagens é uma atividade ligada à Geografia, já que para sua aplicação necessita de uma série de conhecimentos obtidos por meio da Geografia Física, e seus aspectos da geomorfologia, solos, hidrografia dentre outros.

Para representação de fenômenos geográficos a cartografia de paisagens dispõe de uma série de recursos que permitem diferentes representações e interpretações. Em detrimento da disponibilidade e boa qualidade de dados temáticos e da alta resolução das imagens de satélite ou das fotografias aéreas disponíveis, em alguns casos não há necessidade da pesquisa de campo. No entanto como aponta Cavalcanti (2014) para elaborar um mapeamento detalhado, é necessário seguir um conjunto de etapas e subetapas que vão desde o planejamento da pesquisa de campo até a elaboração da carta.

O presente estudo trata sobre os impactos decorrentes da implantação do eucalipto no município de Matões/MA. Questionou-se então como o plantio de eucalipto está afetando a dinâmica da paisagem no município? Será que a implantação dessa monocultura leva em conta as características naturais da área em que está instalada? A pesquisa tem como objetivo estudar a dinâmica da paisagem sob influência dos impactos decorrentes da introdução do cultivo do eucalipto no município de Matões/MA entre 2008 e 2015.

\section{METODOLOGIA}

O desenvolvimento da pesquisa de abordagem quali-quantitativa, contou com os procedimentos de revisão bibliográfica, pesquisa de campo e fase de gabinete, utilizando técnicas do sensoriamento remoto e geoprocessamento. Foi realizada pesquisa de campo para observação, marcação de pontos com receptor GPS, registro fotográfico e preenchimento de planilha.

A fase de gabinete consistiu na elaboração de mapas por meio da aquisição de imagens orbitais adquiridas gratuitamente no site do Instituto de Pesquisas Espaciais - INPE por meio dos sensores Landsat 5 (capturada em 02/08/2008) e Landsat 8 (capturada em 08/07/2015) a partir da composição das bandas espectrais 3, 4 e 5 dos referidos sensores com resolução espacial de 30 
metros, combinadas com o trabalho de campo. O sistema de coordenadas adotado para a base cartográfica foi a UTM, empregando-se o Datum Sirgas 2000.

O período escolhido para análise da dinâmica da paisagem evidencia a estação seca, na qual se encontrou imagens com menor cobertura de nuvens, condição essencial para interpretação de alvos. Estas passaram por técnicas de processamento de imagens no software ArcGis 9.0 (modelo linear de mistura espectral, segmentação e classificação), interpretação visual e técnicas de geoprocessamento.

\section{RESULTADOS E DISCUSSÃO}

\subsection{Localização e caracterização da área de estudo}

A cidade de Matões está localizada nos cerrados maranhenses, inserida na microrregião de Caxias (mapa 1) e áreas de seu território vêm sendo utilizados para implantação de monoculturas com destaque para a produção de eucalipto na mesorregião Leste maranhense.

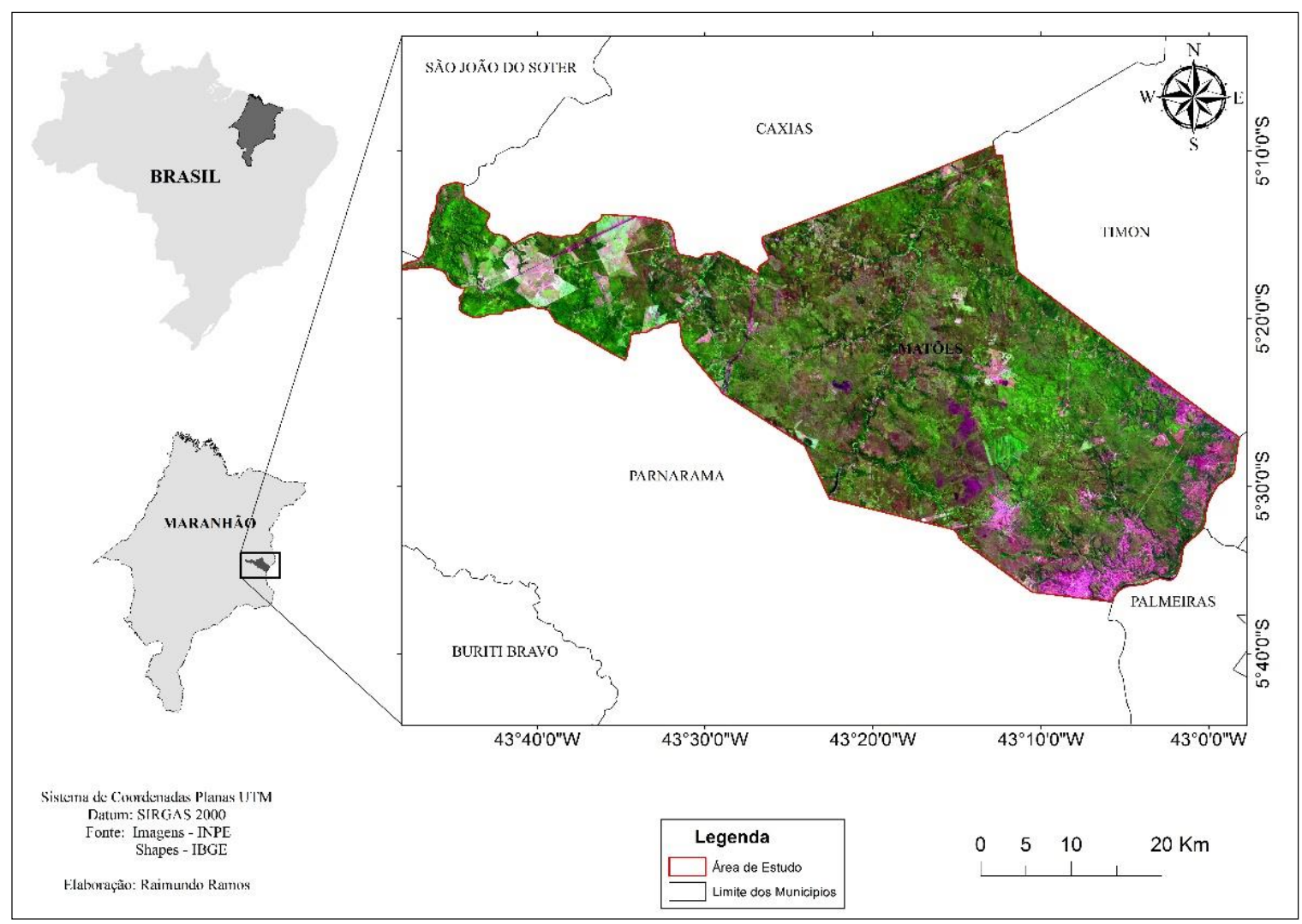

Mapa 01. Localização do município de Matões no Estado do Maranhão/Brasil. Fonte: Andrade (2015).

Possuindo uma área territorial de $2.107,403 \mathrm{Km}^{2}$, o município limita-se ao norte com Timon, ao sul com a cidade de Parnarama, ao leste com o rio Parnaíba e Teresina e ao oeste com Caxias (MARANHÃO, 2010). Com população estimada pelo censo 2010/IBGE em torno de 31.015 habitantes apresenta densidade demográfica de 15,65 habitantes $/ \mathrm{km}^{2}$, destes aproximadamente $36 \%$ 
vivem na zona urbana e $64 \%$ vivem na zona rural (IBGE, 2010). Os aspectos predominantes na paisagem natural são descritos no quadro 01 .

Quadro 01. Síntese dos aspectos naturais do município de Matões/MA.Fonte: Correia Filho (2011).

\begin{tabular}{|c|l|}
\hline \multicolumn{2}{|c|}{ AspectospredominantesnaPaisagem } \\
\hline Geologia & $\begin{array}{l}\text { Grupo Balsas: Formações Piaú, Pedra de Fogo e Motuca; } \\
\text { Grupo Mearim: formação Corda e formação Sardinha. }\end{array}$ \\
\hline Geomorfologia & Feições geomorfológicas: áreas aplainadas, testemunhos tabulares, chapadões e chapadas. \\
\hline Hidrografia & $\begin{array}{l}\text { Bacia hidrográfica do rio Parnaíba: riachos Socovão, do Gentil, da Tapera, da Garapa, Prá Quê, } \\
\text { Gameleira, Itapecuruzinho, São Pedro, dentre outros. }\end{array}$ \\
\hline Clima & $\begin{array}{l}\text { Clima predominante tropical (AW') subúmido seco com dois períodos bem definidos, um chuvoso e } \\
\text { outro seco. }\end{array}$ \\
\hline Solo & Solos predominantes: latossolo amarelo e argissolo, arenosos e areno-argilosos. \\
\hline Vegetação & Domínio do cerrado: cerrado, cerradão e campo sujo; floresta estacional decidual com babaçu. \\
\hline
\end{tabular}

O quadro 01 sintetiza os principais aspectos da paisagem que predominam no município de Matões. O conhecimento da área de estudo, considerando a interação dos aspectos naturais que a compõe, fornece informações importantes que subsidiam a elaboração de estudos da dinâmica e funcionamento da paisagem na perspectiva ambiental.

\subsection{Espacialização da monocultura do eucalipto}

Para a elaboração dos mapas foram definidas quatroclasses: água, solo exposto e plantações (eucalipto). A observação da paisagem no campo trouxe importante consideração sobre sua diversidade, e que não foram possíveis inferir por meio de geoprocessamento. Os mapas elaborados integraram em uma única base de dados, as informações espaciais provenientes dos dados cartográficos, imagens de satélite e da pesquisa de campo visando identificar os padrões de uso da terra na área, e identificar pontos de expansão da cultura do eucalipto na área do município, e analisar a dinâmica da paisagem local pela introdução da monocultura.

O mapeamento possibilitou o detalhamento dos aspectos naturais predominantes no município de Matões demonstrando as áreas de expansão da atividade. Como intuito principal de reconhecer a distribuição espacial da monocultura do eucalipto no município, bem como analisar sua expansão, utilizando como base os procedimentos da cartografia de paisagens. O ano de 2008 representa o momento de implantação do eucalipto no município, e o mapa 2 traz a distribuição das quatro classes representando a distribuição das mesmas na paisagem do município no referido ano. 


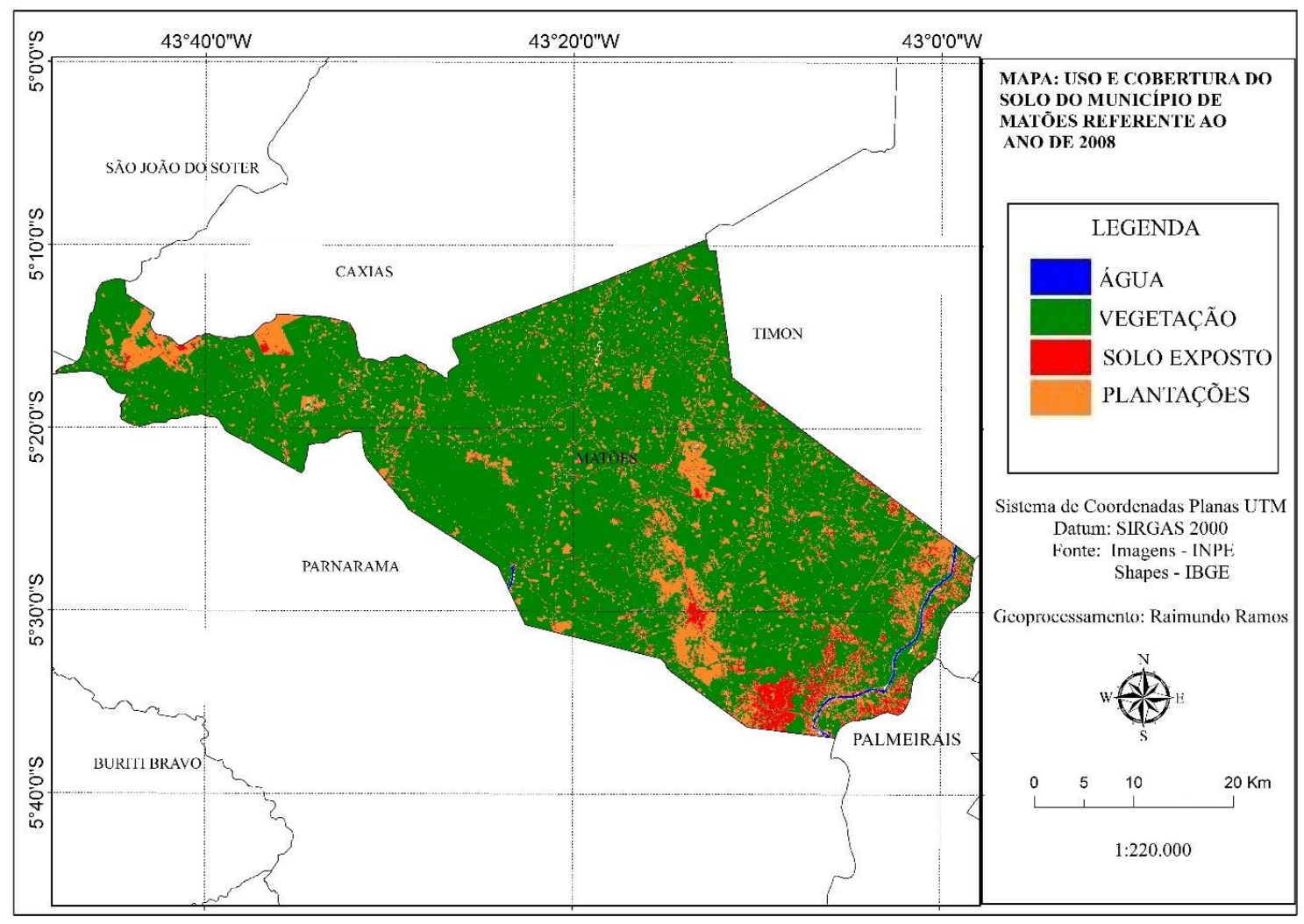

Mapa 02. Uso e cobertura do solo no município de Matões referente ao ano de 2008. Fonte: Andrade, 2015.

Em 2008, dos 19.763 hectares (área urbana e rural) considerados, a vegetação representa 48,51\% (9.585 ha), solo exposto 16,14\% (3.190 ha), e a água representa 3,88\% (767 ha) do território analisado, o uso do território para cultivo do eucalipto representou $31,47 \%$ (6.221 ha) conforme aponta a tabela 01.

Tabela 01. Classificação do uso e cobertura da terra em Matões no ano de 2008. Fonte: Andrade (2015).

\begin{tabular}{|c|c|c|c|}
\hline Classes & Nome & Área (ha) & $\%$ \\
\hline 1 & Vegetação & 9.585 & 48,51 \\
\hline 2 & Solo exposto & 3.190 & 16,14 \\
\hline 3 & Plantação de eucalipto & 6.221 & 31,47 \\
\hline 4 & Água & 767 & 3,88 \\
\hline \multicolumn{2}{|c|}{ Total } & 19.763 & 100 \\
\hline
\end{tabular}

De acordo com as classes selecionadas para o ano de 2008, o que predominou foi a classe 1 - vegetação, que corresponde a 48,51\% da área do município. Em seguida a classe 3 - plantações de eucalipto com $31,47 \%$ da paisagem analisada. A classe 2 - solo exposto corresponde $16,14 \%$ do total e a classe 4 - água representou $88 \%$ do total. Esses dados percentuais foram adquiridos por meio de cálculo matemático através do software ArcGis 9.0 tendo como base o mapa elaborado. Com análise do mapa 02 e tabela 01 fica evidente a presença do eucalipto representando $31,47 \%$ de área com o cultivo. Para início do cultivo extensas áreas foram desmatadas para que pudessem dar 
lugar as plantações, o que representou um impacto na paisagem pela redução da vegetação consequentemente deixando o solo exposto.

Apesar do reflorestamento da área com o eucalipto, isso não representa o retorno da dinâmica original, uma vez que a vegetação original é heterogênea e a monocultura tem como principal característica a substituição de extensas áreas por plantações homogêneas com um único cultivo, o que pode interferir na dinâmica da paisagem. A fim de identificar a expansão do cultivo no município em um intervalo de sete anos o mapa 03 traz a distribuição das quatro classes no ano de 2015.

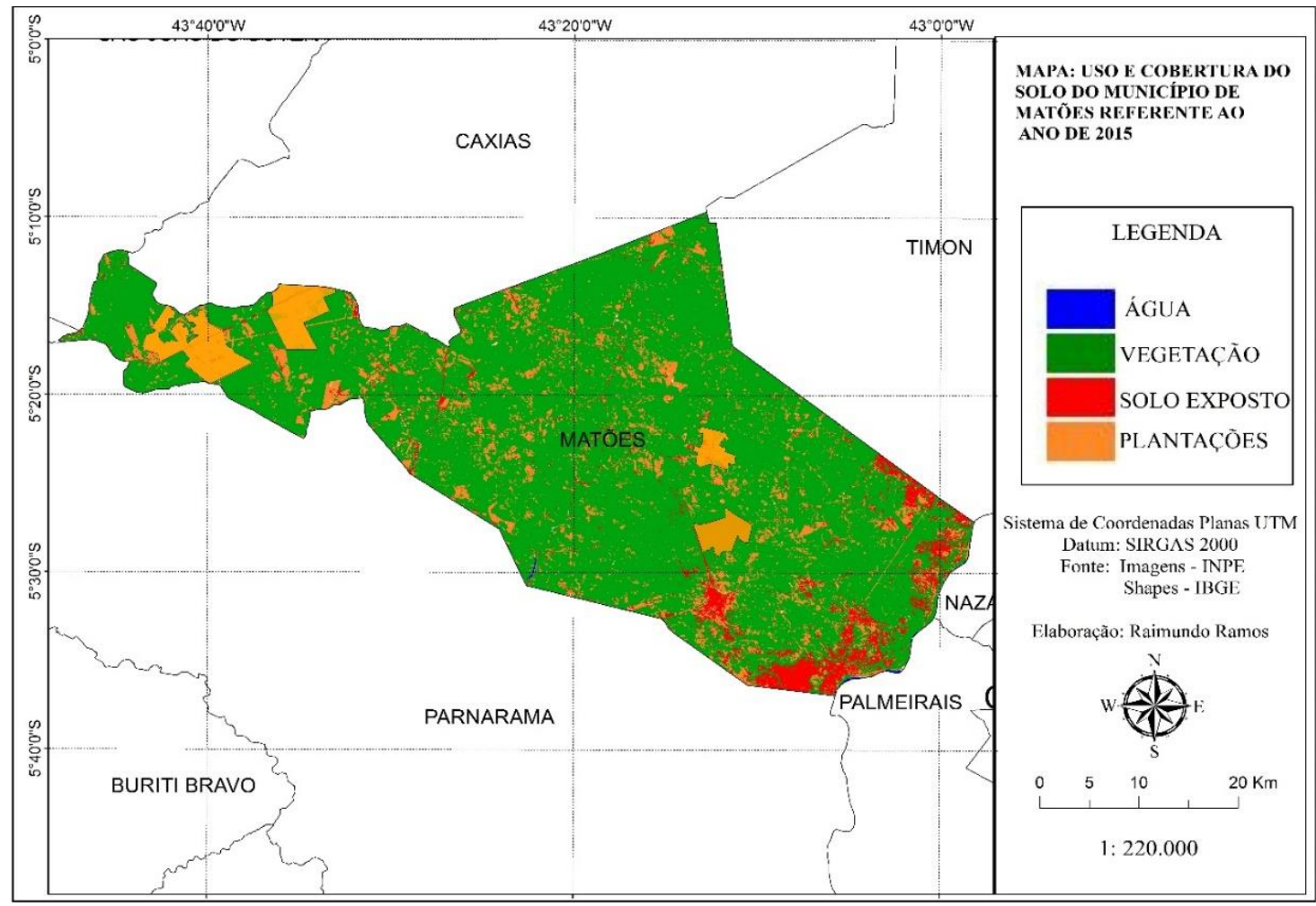

Mapa 03. Uso e cobertura do solo no município de Matões referente ao ano de 2015.Fonte: Andrade (2015).

Em 2015, dos 19.763 hectares considerados, a classe de vegetação representa 50,3\% (9.938 ha), a de solo exposto $11,03 \%$ (2.180 ha), as de água 0,33\% (67 ha) e o uso da terra para cultivo do eucalipto representou $38,34 \%$ (7.578 ha) da paisagem analisada conforme aponta a tabela 02 .

Tabela 02. Classificação do uso e cobertura da terra em Matões no ano de 2015. Fonte: Andrade (2015).

\begin{tabular}{c|c|c|c}
\hline Classes & Nome & Área (ha) & \% \\
\hline 1 & Vegetação & 9.938 & 50,3 \\
2 & Solo exposto & 2.180 & 11,03 \\
3 & Plantação de eucalipto & 7.578 & 38,34 \\
4 & Água & 67 & 0,33 \\
\hline \multicolumn{7}{c}{ Total } & $\mathbf{1 9 . 7 6 3}$ & $\mathbf{1 0 0}$ \\
\hline
\end{tabular}


Comparando o uso e cobertura da terra entre os anos de 2008 e 2015 é possível verificar modificações contundentes. Os dados revelam que houve um aumento de algumas classes e decréscimo de outras, o que pode ser explicado mediante vários fatores. O crescimento das áreas destinadas ao cultivo do eucalipto teve aumento de 6,87\% e a vegetação natural recuperou-se 1,79\%. Em comparação houve decréscimo de 5,11\% do solo exposto e 3,55\% do total de água superficial disponível, conforme aponta a tabela 03.

Tabela 03. Variação do uso e cobertura da terra no período 2008-2015. Fonte: Andrade (2015).

\begin{tabular}{c|c|c|c|c}
\hline \multirow{2}{*}{ Classes } & \multirow{2}{*}{ Nome } & \multicolumn{2}{|c|}{ Área (ha) } & \multirow{2}{*}{$\begin{array}{c}\text { Variação no } \\
\text { período (\%) }\end{array}$} \\
\cline { 3 - 4 } & & $\mathbf{2 0 0 8}$ & $\mathbf{2 0 1 5}$ & 1,79 \\
2 & Vegetação & 9.585 & 9.938 & $-5,11$ \\
3 & Solo exposto & 3.190 & 2.180 & 6,87 \\
4 & Plantação de eucalipto & 6.221 & 7.578 & $-3,55$ \\
\hline & Água & 767 & 67 & - \\
\hline
\end{tabular}

A comparação entre os dados dos mapas de uso de 2008 e 2015 revelou que houve um aumento da vegetação da área quando comparado com ano de 2008. Uma possível explicação que poderia justificar tal aumento é que áreas de reflorestamento de eucalipto antigas tem resposta espectral semelhante à das matas nativas devido ao seu vigor, diferentemente de áreas novas de reflorestamento.

Isso acontece porque o eucalipto jovem absorve muita água para seu desenvolvimento, o que reflete em uma alta resposta espectral de sua copa nas bandas 3 e 4 do sensor TM do Landsat, o que permite sua diferenciação das florestas naturais. Quando atinge a maturidade, o eucalipto absorve uma quantidade de água semelhante à de florestas naturais e sua copa passa apresentar vigor vegetativo semelhante ao de vegetação natural. Deste modo, apesar do esforço de campo, é possível que algumas manchas de reflorestamento tenham sido mapeadas como áreas de vegetação natural.

Em contrapartida, houve redução da classe solo exposto quando comparado os dois mapas, uma explicação para esse fato se dá pela intensificação do processo de reflorestamento com eucalipto, que consequentemente reduz a quantidade de exposição do solo da região. Ademais, destaca-se que nesse processo de reflorestamento, o solo é corrigido com uso de alguns produtos, e nem sempre a cobertura do mesmo vai indicar uma boa qualidade, podendo ocorrer perda de nutrientes e acelerar o processo de erosão. Por se tratar do reflorestamento com uma mesma espécie pode ocorrer mudança na dinâmica da área, pois a vegetação anterior era heterogênea mantendo o equilíbrio entre a fauna e a flora da região. Com a supressão desta, a dinâmica natural foi afetada pois não se levou em consideração os valores presentes na área ocasionando uma série de impactos. 
A redução da quantidade de água superficial apresentada na comparação dos mapas de uso, explica-se que em imagens Landsat os cursos d'água de pequeno porte são difíceis de serem detectados, e são estes tipos de cursos existentes no município em estudo. Portanto, o resultado sobre esta classe, pode estar equivocado já que a área do município é drenada por diversos riachos, mas o presente estudo não possui dados suficientes para inferir a real situação destes, não podendo precisar possíveis impactos sobre os mesmos, decorrentes do cultivo do eucalipto. Ressalta-se que durante a pesquisa de campo e conversas com os moradores revelaram que diversos riachos e lagoas secaram após o início do cultivo.

\section{CONSIDERAÇÕES FINAIS}

Considerou-se que o estudo cartográfico de paisagens por meio de mapas de uso da terra, permite a compreensão não apenas da organização espacial dos fenômenos geográficos, mas também a dinâmica, evolução e mudanças das paisagens, destacando a importância da pesquisa de campo para cartografia de paisagens e para a presente pesquisa que consistiu na observação e registro dos atributos naturais e antrópico da paisagem.

No estudo realizado foi fundamental o tratamento dos dados em ambiente SIG, podendo-se constatar os principais impactos observados na paisagem com o plantio do eucalipto. Posteriormente,o uso dessas informações contribuiu para elaboração dos mapas de uso da terra possibilitando a visualização da paisagem do município de maneira integrada por meio dos recursos da cartografia da paisagem.

\section{REFERÊNCIAS}

BERTRAND, G. Paisagem e Geografia Física Global, Esboço Metodológico. R. RA'E GA, Curitiba, UFPR, n. 8, p. 141-152, 2004.

CAVAlCANTI, L. C. S. Cartografia de paisagens: fundamentos. São Paulo: Oficina de textos, 2014.

CORREIA FILHO, F. L. Projeto de abastecimento por água subterrânea, Estado do Maranhão: relatório diagnóstico do município de Matões. Teresina: CPRM, 2011. 31 p.

INSTITUTO BRASILEIRO DE GEOGRAFIA E ESTATÍSTICA - IBGE. Censo 2010: Maranhão. 2010. Disponível em: <www.ibge.gov.br/cidadesat/topwindow.htm?1>. Acesso em: 20. jan. 2015.

MARANHÃO. Plano Territorial de desenvolvimento Sustentável. Território Cocais. São Luís: COOSPAT, 2010. 
VITTE, A. C. ODesenvolvimento do Conceito de Paisagem e a sua inserção na Geografia Física. Mercator - Revista de Geografia da UFC, Ano 06, n. 11, Fortaleza, 2007.

Recebido em: 14/08/2016

Aceito para publicação em: 01/10/2016 